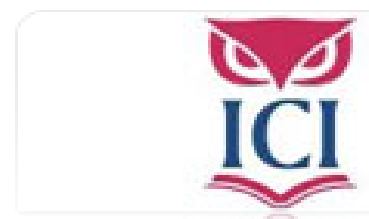

IUS. Revista del Instituto de Ciencias Jurídicas de Puebla A.C.

ISSN: 1870-2147

revista.ius@hotmail.com

Instituto de Ciencias Jurídicas de Puebla A. C.

México

Martínez Sierra, José Manuel

Elecciones, cambio político y reforma constitucional en Nicaragua

IUS. Revista del Instituto de Ciencias Jurídicas de Puebla A.C., núm. 21, 2008, pp. 119-158 Instituto de Ciencias Jurídicas de Puebla A. C.

Puebla, México 


\section{ELECCIONES, CAMBIO POLÍTICO Y REFORMA CONSTITUCIONAL EN NICARAGUA}

José Manuel Martínez Sierra*

1. Introducción

2. El contexto del proceso electoral del 5 de noviembre de 2006

2.1. Realidad sociopolitica

2.2. Marco jurídico del proceso electoral

2.3. Sistema electoral

2.4. Poder electoral

2.5. El procedimiento de escrutinio

3. El momento preelectoral

3.1. Candidaturas y campaña electoral

3.2. Las encuestas preelectorales

3.3. La vulneración del silencio electoral

3.4. La injerencia extranjera

4. La jornada electoral

4.1. Transcurso de la jornada electoral

4.2. Los observadores electorales

5. Resultados electorales

6. Interpretación de los resultados electorales

6.1. Elecciones a la presidencia y vicepresidencia de la República 6.2. Elecciones a diputados de la Asamblea Nacional, en la circunscripción nacional y en las circunscripciones departamentales y regiones autónomas

6.3. Relaciones exteriores y política económica

7. Reforma constitucional

7.1. La reforma constitucional realizada

7.2. La reforma constitucional futurible

8. Conclusiones

\footnotetext{
* Profesor titular de derecho constitucional. Catedrático "Jean Monnet" de derecho constitucional europeo, Universidad Complutense de Madrid.
} 


\section{RESUMEN}

El presente trabajo estudia el cambio político y la reforma constitucional -pasada y prevista- de Nicaragua en el contexto de polarización de proyectos que vive Latinoamérica: el representado por la "revolución constitucional" y el continuista. Dicho estudio apunta, en su introducción, las variables esenciales que juegan a favor y en contra del cambio político en Latinoamérica; posteriormente describe el proceso de cambio - previo, durante y tras las elecciones-; finalmente concluye extrayendo las variables comunes de las específicas de Nicaragua.

\section{ABSTRACT}

The present work studies the political change and the constitutional reformation -passing and foreseen- of Nicaragua in the context of polarization of projects that Latin America lives: the represented one for the "constitutional revolution" and the represented one for the continuity. This study points, in its introduction, the essential variables that play to favor and against the political change in Latin America; later on it describes the process of change -previous, during and after the elections-; finally it concludes extracting the variable comuneses of the specific ones of Nicaragua.

\section{INTRODUCCIÓN}

Hoy hay dos proyectos claros para la Latinoamérica constitucional y política: la representada por la "revolución constitucional" y la continuista que se encuentra posicionada frente a ella hasta el punto de demonizarla. La "revolución constitucional" entiende que los males que acucian a Latinoamérica, como endémicos y estructurales, solamente podrían resolverse a través de un proceso de cambio radical: que se aparte nítidamente de la alternancia de los partidos e intereses tradicionales y que se apoye en una reforma constitucional e institucional que pase del alfa al omega: que constitucionalice y/o sitúe al débil, mayoritario y marginado histórico y presente, a la sazón, como soberano y horizonte del cambio. En casi todos los países hay fuerzas políticas que asumen este proyecto $\mathrm{y}$, en un número considerable, más que nunca en la historia, dichas fuerzas asumen o han estado cerca -con o sin fraude electoral-de alcanzar el poder.

En la realidad, con influencia de esas dos visiones, se puede dividir Latinoamérica en dos bloques. De un lado, aquel en el que no se ha producido cambio político real y se ha profundizado la línea política existente (Perú con Alan García o México con Felipe Calderón); aquel otro en el que simplemente se ha producido alternancia política formal que, si bien aparentemente importante en términos ideológicos, mantiene la marea estructural de poderes e intereses, y adjetivalmente postula un giro social (Brasil 
con Lula, Uruguay con Tabaré, o Chile, con Lagos o Bachelet); aquel otro también donde formalmente no se produjo una alternancia partitocrática pero, de facto, se han realizado políticas y posicionamientos que suponen un cambio mayor que el de los bloques precedentes (la Argentina de Kirschner); por último, aquel nutrido por países que han iniciado un proceso de "revolución constitucional", en los que claramente se encuentran, por orden alfabético, Bolivia, Ecuador y Venezuela.

No es necesario ser un experto en Latinoamérica para saber que los intereses políticos y económicos de siempre quieren que las cosas sigan como siempre. Para conseguir tal fin, las armas son las de siempre. Entre ellas destacan, en los últimos tiempos, dos: la "neutralización" de los partidos revolucionarios de izquierda históricos y la sofisticación de la (des)legitimación electoral.

La "neutralización" de los partidos revolucionarios de izquierda históricos es la forma más eficaz para amortiguar la incesante rebelión de los pueblos latinoamericanos. La revolución constitucional, como hemos dicho, aunque no se garantice con ello, debe pasar, en buena medida, por la no contaminación del proceso por los partidos de gobierno tradicionales, títeres de la alternancia del cambio formal para que todo siga igual. La no contaminación y éxito del proceso se desenvuelve mejor con los procesos de ruptura radical con el sistema de partidos/intereses tradicionales, como ha ocurrido en Venezuela, Ecuador y, con algunos matices, en Bolivia. Lo mismo habría ocurrido en Perú, aunque entiendo que no en México con el PRD de López Obrador en aquel momento histórico; cuestión distinta sería en el futuro, después de la radicalización que ha sufrido el partido, y su líder, tras el engaño estadunidense y el fraude electoral.

Estos movimientos alternativos enérgicos no han crecido donde la alternancia nunca se produjo o mantenía visos de ser real, estoy pensando en el pt de Lula y el Frente Sandinista de Daniel Ortega. Como sobre este segundo versa el artículo, me pronuncio aquí solamente sobre el primero. En mi opinión personal, el fraude histórico a la alternancia que han significado el Pт brasileño y Lula da Silva debe interpretarse sustantivamente por la neutralización de su energía transformadora en el largo y sinuoso camino hacia el poder: las connivencias con el poder tradicional, político y económico, en poderes públicos estatales y locales; las transas con grupos económicos del propio proyecto Lula en cada proceso electoral perdido; la flexibilización de los principios en el viaje al vivero de votos del centro; y el propio desgaste interno del PT por ser la eterna alternativa. 
Sin entrar en profundidades que nos alejen del tema central, el resultado es que la ilusión del cambio por llegar que significaba el PT, que pese a todo se mantuvo hasta en los miembros críticos que aguantaron hasta ver las acciones del gobierno y ahí formaron el PsoL, va a provocar que se pierdan cuando menos tres mandatos de esperanza (dos de Lula y el del retorno a la alternancia). A ello se añade que dichos años, por la coincidencia con otros procesos, serán irrepetibles.

Respecto a la segunda cuestión, hablo de (des)legitimación electoral, pues el proceso por el cual se intenta impedir el acceso al poder de movimientos no deseados es una combinación que, junto a la plétora de mecanismos de fraude electoral, se acompasa, por delante y por detrás del momento electoral, con el proceso de (des)legitimación electoral que se articula esencialmente a través de la observación electoral y la tergiversación mediática. ${ }^{1}$

Hay serias dudas de que los presidentes electos en México y Perú sean los que ganaron las elecciones, como pasó en los Estados Unidos en el primer mandato de George W. Bush. Los datos y la convicción de fraude llevaron al líder del proyecto del cambio, Andrés Manuel López Obrador, y a los partidos de su coalición, particularmente al suyo, el PRD, a una estrategia que anteponía la legitimad a la legalidad formal y el engaño. Si México y Perú hubiesen caído del lado democrático, ¿dónde estaríamos?

Todo lo dicho aquí pone de manifiesto que el cambio político real necesario en Latinoamérica no pasa por la alternancia, sino por la revolución constitucional, y que ésta pasa por las elecciones y, previamente, por el agotamiento hasta el tuétano de la alternancia tradicional.

Nicaragua es un escenario en el que se ven todas las piezas del puzzle. Hemos tenido unas elecciones, seguidas de una reforma constitucional e institucional, en las que resultó vencedor el Frente Sandinista, de Daniel Ortega, que mantenía visos de ser una alternativa real y, en consecuencia, activó las alarmas reaccionarias. El presente artículo pretende analizar este teatro de operaciones y ver qué enseñanzas pueden extraerse de cara a la reflexión general que da cuerpo a esta introducción.

Las elecciones presidenciales y legislativas se celebraron el 5 de noviembre de 2006 en la República de Nicaragua. En ellas se elegían presidente y vicepresidente del gobierno, diputados a la Asamblea Nacional y

${ }^{1}$ Para mayor detalle sobre esta cuestión, Cfr. J. M. Martínez Sierra, "La gobernabilidad democrática entre el constitucionalismo y la politología", Memoria del Seminario Internacional "Gobernabilidad Democrática, Ed. Gobierno de Oaxaca, México, 2007, pp. 85-108. 
diputados al Parlamento Centroamericano. De estas votaciones, la elección del presidente era la que a priori resultaba más relevante, dado el corte presidencialista del sistema político nicaragüense; sin embargo, la reforma constitucional, que determinó entre otros una rebaja en el porcentaje de votos necesario para alcanzar la presidencia, confirió una importancia sobrevenida a la composición de la Asamblea Nacional, al convertir el sistema político en semiparlamentario/semipresidencialista, como explicaremos a lo largo de este texto.

El presente artículo, en primer lugar, pone en contexto el proceso electoral del 5 de noviembre de 2006. Esta contextualización se hace a través de una exposición de la realidad sociopolítica, del marco legal en el que se desenvuelve, del sistema electoral que se aplica y del funcionamiento de la administración electoral. A continuación se procede a la descripción del panorama electoral previo a la celebración de las elecciones, destacando los hechos más controvertidos que sucedieron en el transcurso de la campaña: la ruptura del silencio electoral en determinados medios de comunicación nicaragüenses y la injerencia de los Estados Unidos en el proceso electoral. En tercer lugar se procede a la valoración de la jornada electoral y se revisa la labor desempeñada y los informes emitidos por organismos nacionales e internacionales que desplegaron observadores. Seguidamente se exponen los resultados finales, que otorgaron la presidencia de la República en primera vuelta a Daniel Ortega, líder del partido sandinista (FSLN), y se efectúa un análisis de dichos resultados. Por último, con carácter previo a las conclusiones finales, se aborda la cuestión de la reforma constitucional, tanto la realizada con carácter previo al proceso como la que se ha venido apuntando en los primeros meses del gobierno sandinista.

\section{El contexto del proceso electoral del $\mathbf{5}$ de noviembre de 2006}

\subsection{ReALIDAD SOCIOPOLÍtica}

Nicaragua es uno de los países menos poblados del continente americano, con una densidad demográfica de apenas 43 habitantes por $\mathrm{km}^{2}$, que se concentran principalmente en la mitad occidental del país y se reparten casi por igual entre las zonas urbanas (57\%) y las rurales (43\%). El 77\% de los nicaragüenses son mestizos, un 6\% blancos, un $9 \%$ negros, y son indigenas el 8\% restante. Su población, según el censo de 2005, asciende 
a 5,142,098 habitantes. De ellos, componían el padrón de votantes para las elecciones del 5 de noviembre un total de 3,665,141 (ver tabla 1), de los cuales, como se muestra en la mencionada tabla, finalmente acudieron a las urnas 2,244,215 votantes, lo que supone una participación del 61.23\%. Administrativamente, el territorio de Nicaragua está dividido en quince departamentos y dos regiones autónomas (ver tabla 1), con un total de 153 municipios en el nivel de la administración local. Managua es la capital administrativa del país, y también la ciudad donde se concentra casi el 20\% del total de la población (según el censo de 2006, la población de Managua asciende a 937,489 habitantes). Otras ciudades importantes son León, Masaya, Matagalpa y Granada.

TABLA 1: Población electoral

\begin{tabular}{|l|c|c|c|c|}
\hline \multicolumn{1}{|c|}{ Departamento } & Centros & JRV & Padrón electoral & Votos* \\
\hline Boaco & 190 & 358 & 108387 & 57089 \\
\hline Carazo & 144 & 368 & 121084 & 76031 \\
\hline Chinandega & 345 & 886 & 286380 & 174259 \\
\hline Chontales & 196 & 386 & 117404 & 74383 \\
\hline Estela & 210 & 491 & 150017 & 102575 \\
\hline Granada & 144 & 392 & 127585 & 81855 \\
\hline Jinotega & 280 & 648 & 204172 & 133704 \\
\hline León & 369 & 885 & 275522 & 165019 \\
\hline Madriz & 135 & 284 & 89337 & 68003 \\
\hline Managua & 605 & 2665 & 947337 & 605041 \\
\hline Masaya & 154 & 587 & 202968 & 135815 \\
\hline Matagalpa & 440 & 991 & 307970 & 186622 \\
\hline Nueva Segovia & 194 & 434 & 136655 & 85470 \\
\hline RAAN & 298 & 589 & 181435 & 77088 \\
\hline RAAS & 349 & 694 & 213551 & 103577 \\
\hline Río San Juan & 79 & 212 & 68948 & 39799 \\
\hline Rivas & 164 & 404 & 126389 & 77885 \\
\hline & 4296 & 11274 & 3665141 & 2244215 \\
\hline Total & & & & \\
\hline
\end{tabular}

* Tipo de elección: Presidente y vicepresidente; última actualización: 7 de noviembre de 2006. Fuente: Consejo Supremo Electoral de Nicaragua (www.cse.gob.ni/). 


\subsection{Marco JuRídico del proceso electoral}

Las tres normas principales de aplicación son:

- La Constitución Politica de la República de Nicaragua de 1987, con sus sucesivas reformas. ${ }^{2}$

- La Ley Electoral, Ley No. 331, de 19 de enero de 2000.

- La Ley de Identificación Ciudadana, Ley No. 152, de 5 de marzo de 1993.

Además de las tres grandes normas precitadas, hay toda una serie de normas y disposiciones de rango infralegal, así como protocolos de actuación, que terminan de conformar el marco jurídico de las elecciones del 5 de noviembre, a saber: la Normativa de Impugnaciones, el Reglamento de Ética Electoral, las Normativas de Fiscales y de Representantes de Partidos, las Normas para la Administración del Financiamiento, Normas de Procedimiento sobre Peticiones, Quejas, Denuncias durante Campaña Electoral 2006, el Reglamento de Observación, el Calendario Electoral para Elecciones Nacionales 2006, la Convocatoria a Elecciones Nacionales 2006, y, por último, cabe citar la jrv, que es el documento que utilizaron el día de las elecciones los miembros de las Juntas Receptoras de Voto, es decir, el equivalente a las mesas electorales.

\subsection{Sistema electoral ${ }^{3}$}

En las elecciones del 5 de noviembre de 2006 los nicaragüenses estaban convocados a elegir presidente y vicepresidente de la República, 90 diputados (20 nacionales y 70 departamentales) y 20 diputados del Parlacén (Parlamento Centroamericano www.parlacen.org.gt/).

a) La elección de presidente y vicepresidente se realiza con elección directa, por sistema uninominal mayoritario a doble vuelta y con circunscripción nacional. La Constitución, tras la reforma llevada a cabo en el año 2000, estipula que es necesario obtener un mínimo del 35\% de votos, siem-

\footnotetext{
${ }^{2}$ Como se analiza posteriormente, es especialmente relevante la reforma constitucional realizada por Ley No. 330, de 19 de enero de 2000, de Reforma parcial a la Constitución Política de la Republica de Nicaragua. Su importancia reside en que, entre otras modificaciones, teniendo especial relevancia en lo aquí analizado, dicha reforma altera a la baja el porcentaje de votos necesario para alzarse con la presidencia de la República.

${ }^{3}$ Para una visión comparada del mismo, ver J. M. Martínez Sierra, "Los sistemas electorales desde una perspectiva comparada”, IUS, Revista del Instituto de Ciencias Jurídicas de Puebla, No. 18, 2007, pp. 20-38.
} 
pre que se supere en un 5\% al segundo candidato más votado, o en todo caso si se obtiene el 40\%. ${ }^{4}$ En el supuesto de no alcanzar estos porcentajes, está prevista la realización de una segunda vuelta en un plazo de 45 días; en ella pueden concurrir únicamente las dos candidaturas más votadas. En esta segunda vuelta rige la mayoría simple estricta: resultará elegido el que obtenga mayor número de votos con independencia el porcentaje alcanzado y la diferencia de votos respecto del segundo candidato.

b) En cuanto a la elección de diputados a la Asamblea Nacional, el reparto de escaños entre las fuerzas políticas se hace de acuerdo con el siguiente sistema de representación proporcional:

- En cuanto a los 20 diputados de carácter nacional, su elección se determina mediante un sistema de representación proporcional por cociente electoral nacional. Dicho cociente, según dispone la Ley Electoral vigente $^{5}$ se determina dividiendo por 20 el número total de votos válidos, dado que 20 es el número de escaños en juego en la circunscripción nacional. Una vez hallado el cociente, se asignan a cada partido tantos escaños como veces alcance el cociente electoral nacional. Posteriormente, y dado que se utiliza un sistema de lista cerrada, resultan elegidos de cada lista los primeros candidatos a diputados propietarios, con sus correspondientes suplentes, hasta completar el número de escaños obtenido por la lista.

- Los escaños no repartidos se asignan por el sistema de la media mayor, a saber: se ordenan de nuevo los votos obtenidos por cada partido de mayor a menor y el siguiente escaño se asignará al partido que obtenga la media mayor, la cual se halla dividiendo el número de votos válidos obtenidos por cada partido entre el número de escaños obtenidos a través de la operación del cociente más uno. Esta operación se repetirá sucesivamente hasta que se complete el número total de escaños.

- Los 20 diputados departamentales se reparten territorialmente del modo que se recoge en la tabla 2 entre las quince provincias y las dos regiones autónomas (la Región Autónoma del Atlántico Norte, RAAN, y la del Atlántico Sur, RASS) que componen el mapa político de Nicaragua:

${ }^{4}$ Art. 147, primer párrafo.

${ }^{5}$ Art. 146 de la Ley Electoral, Ley No. 331 de 19 de enero de 2000. 
TABLA 2: Reparto de diputados por departamentos

\begin{tabular}{|l|c|l|c|}
\hline \multicolumn{1}{|c|}{ Departamento } & Diputados & Departamento & Diputados \\
\hline Boaco & 2 & Managua & 19 \\
\hline Carazo & 3 & Masaya & 4 \\
\hline Chinandega & 6 & Matagalpa & 6 \\
\hline Chontales & 3 & Nueva Segovia & 2 \\
\hline Estela & 3 & RAAN & 3 \\
\hline Granada & 3 & RAAS & 2 \\
\hline Jinotega & 3 & Rio San Juan & 1 \\
\hline León & 6 & Rivas & 2 \\
\hline Madriz & 2 & Total & 70 \\
\hline
\end{tabular}

Fuente: Elaboración propia.

La asignación de escaños por circunscripción departamental sigue la misma fórmula del cociente electoral, pero aquí en relación con los diputados a elegir en el nivel departamental y regional. Por lo tanto, el cociente electoral en este caso será el derivado de dividir el total de los votos válidos emitidos en el departamento o la región autónoma entre el número de escaños que le corresponden (ver tabla 2).

En la circunscripción donde se elige sólo a un diputado (Río San Juan), si ningún partido o alianza alcanza el cociente electoral, el escaño disputado corresponde al que obtuvo la mayoría de los votos válidos en la circunscripción. En el mismo caso, si dos o más partidos empatan en número de votos, le corresponde el escaño al partido más votado a nivel nacional.

En las circunscripciones en donde se eligen dos diputados (Boaco, Madriz, Nueva Segovia, Rivas y RAAS) y ningún partido o alianza alcanza el cociente electoral, se le otorgarán los escaños a las dos listas más votadas, un diputado para cada partido. En caso de que uno de los candidatos hubiera completado un cociente electoral y obtuviera un diputado, el otro escaño se le otorgará al partido que obtuvo la siguiente mayor votación.

Igual ocurre en el caso de los diputados por circunscripción nacional: se declaran electos los primeros de la lista, hasta alcanzar el número de escaños obtenidos por cada partido, y los escaños que falten se distribuyen a los que resulten con la media mayor. 
c) Los 20 diputados ante el Parlamento Centroamericano se eligen por circunscripción nacional en la misma fecha de la primera vuelta de las elecciones del presidente y vicepresidente de la República, y el reparto de escaños entre partidos sigue el mismo mecanismo que el utilizado para los diputados de carácter nacional, según disponen los artículos 150 y 151 de la Ley Electoral.

\subsection{Poder electoral}

Está integrado por el Consejo Supremo Electoral (cse) (Www.cse.gob.ni/) y los demás organismos electorales subordinados (Art. 169, Constitución), es decir, los consejos electorales descentralizados a nivel departamental o regional y local, y las Juntas Receptoras de Votos (JRV).

- Consejo Supremo Electoral:

El CSE está compuesto por "siete Magistrados propietarios y tres Magistrados suplentes, elegidos por la Asamblea Nacional de listas separadas propuestas por el presidente de la República y por los diputados de la Asamblea Nacional, en consulta con las Asociaciones Civiles pertinentes" (Art. 6, Ley Electoral). Resultado de los pactos entre fuerzas políticas, la composición actual del CSE es de cuatro miembros propuestos por los liberales: el presidente Roberto Rivas y los magistrados Luis Benavides, René Herrera y José Marenco; y los otros tres magistrados propietarios, propuestos por el FSLN: el vicepresidente del CSE Emmet Lang, y los magistrados José Luis Villavicencio y José Miguel Córdoba. Estos magistrados son elegidos por un periodo de cinco años, pudiendo ser reelegidos, como ha sucedido tanto en el caso de los tres magistrados sandinistas como en el del propio Rivas, presidente del CSE. $^{6}$

${ }^{6}$ Según el Art. 173 de la Constitución de la República de Nicaragua, al csE le corresponden las siguientes atribuciones:

1. Organizar y dirigir las elecciones, plebiscitos o referendos que se convoquen de acuerdo con lo establecido en la Constitución y en la ley.

2. Nombrar a los miembros de los demás organismos electorales de acuerdo con la Ley Electoral.

3. Elaborar el calendario electoral.

4. Aplicar las disposiciones constitucionales y legales referentes al proceso electoral. Asimismo velar sobre el cumplimiento de dichas disposiciones por los candidatos que participen en las elecciones generales y municipales. En el caso de las elecciones municipales, para ser electo Alcalde, Vice-Alcalde y Concejal requiere haber residido o trabajado en forma continuada en el país los cuatro años anteriores a la elección, salvo que cumpliere Misiones Diplomáticas o estudio en el extranjero. Además, se requiere haber residido en forma continuada los dos últimos años en el municipio por el cual se pretende salir electo. 5. Conocer y resolver en última instancia de las resoluciones que dicten los organismos electorales subordinados y de las reclamaciones e impugnaciones que presenten los partidos políticos.

6. Dictar de conformidad con la ley de la materia, las medidas pertinentes para que los procesos elec- 
- Consejos electorales descentralizados en los distintos niveles administrativos:

En primer lugar, existen quince Consejos Electorales Departamentales (CED), uno en cada uno de los quince departamentos de la República. El equivalente en cada una de las dos regiones autónomas (la Región Autónoma del Atlántico Norte y para la Región Autónoma del Atlántico Sur) son los Consejos Electorales Regionales (CER). Por último, en cada uno de los 153 municipios del país existe un Consejo Electoral Municipal (сем).

- Juntas Receptoras de Votos:

Son el equivalente a las mesas electorales. La Ley Electoral en su Art. 32 dispone que deben establecerse en número suficiente en cada municipio y que podrán votar en cada JRV como máximo 400 electores. De igual forma, el citado artículo de la Ley Electoral dispone que las JRV se instalarán, con carácter general, en centros escolares, casas comunales y edificios públicos. Asimismo, y en cuanto a las condiciones de estas mesas en las que los ciudadanos ejercitan su derecho al sufragio, el Consejo Supremo Electoral debe garantizar en cada JRV al menos dos recintos de votación, es decir, dos cabinas que garanticen el voto secreto, siempre que las condiciones del lugar lo permitan.

En cuanto a la composición de las mesas, estarán integradas por un presidente y tres miembros, con sus respectivos suplentes (Art. 24, Ley Electoral), todos ellos nombrados por el correspondiente Consejo Electoral Municipal (Art. 25, Ley Electoral). Resulta llamativo que la designación de los miembros de las JRv, según el procedimiento descrito en el Art. 16 de la

torales se desarrollen en condiciones de plena garantía.

7. Demandar de los organismos correspondientes, condiciones de seguridad para los partidos políticos participantes en las elecciones.

8. Efectuar el escrutinio definitivo de los sufragios emitidos en las elecciones, plebiscitos y referendos, y hacer la declaratoria definitiva de los resultados.

9. Dictar su propio reglamento.

10. Organizar bajo su dependencia el Registro Central del Estado Civil de las Personas, la cedulación ciudadana y el padrón electoral.

11. Otorgar la personalidad jurídica como partidos políticos, a las agrupaciones que cumplan los requisitos establecidos en la ley.

12. Cancelar la personalidad jurídica de los partidos políticos que no obtengan al menos un cuatro por ciento del total de votos válidos en las elecciones de autoridades generales, y cancelar o suspender la misma en los otros casos que regula la ley de la materia.

13. Vigilar y resolver los conflictos sobre la legitimidad de los representantes y directivos de los partidos políticos y sobre el cumplimiento de disposiciones legales que se refieran a los partidos políticos, sus estatutos y reglamentos.

14. Las demás que le confieran la Constitución y las leyes.

De las resoluciones del Consejo Supremo en materia electoral no habrá recurso alguno, ordinario ni extraordinario. 
Ley Electoral, corresponde a los partidos políticos en el siguiente sentido: el presidente, el primer miembro y los suplentes de ambos se nombran alternativamente de entre los partidos políticos que hubiesen obtenido el primero y segundo lugar en las últimas elecciones generales que se hayan celebrado, con base en ternas presentadas por dichos partidos. Estos partidos son el Partido Liberal Constitucionalista (PLC) y el Frente Sandinista de Liberación Nacional (FSLN). La Ley electoral no especifica cómo se deben repartir las posiciones del segundo miembro de las JRV entre los demás partidos, y sólo establece que se tomará en cuenta el pluralismo político.

El número de Juntas Receptoras de Votos en las elecciones del 5 de noviembre ascendió a 11,274, ubicadas en 4,296 Centros de Votación (ver tabla 1).

\subsection{El PROCEDIMIENTO de ESCRUTINIO}

El escrutinio se centraliza por el Centro Nacional de Cómputos (CNc) del Consejo Supremo Electoral, según dispone el Art. 188 de la Ley Electoral. Los presidentes de cada uno de los 153 Consejos Municipales Electorales son los únicos autorizados para la transmisión al cNc de las actas de votación expedidas por las respectivas Juntas Receptoras de Votos. Esta transmisión se realiza alternativamente a través de tres vías: intranet, red pública de fax y satélite.

Los datos de las actas llegan como imágenes al servidor del área de transmisión del cNc, servidor que se administra por la empresa de telefonía del país, que es privada y española (Telefónica). Ese proceso de volcado de datos es vigilado en todo momento por funcionarios del CSE y por fiscales de los distintos partidos políticos. Desde ese servidor privado, los datos son trasladados a otro servidor, que esta vez es público, del CSE, siendo archivados como un back-up los datos inicialmente recibidos de la operadora privada, para eventuales controles posteriores.

El área de cómputo del cNc está integrada por cuatro departamentos:

- En el departamento de recepción es donde se incorporan todos los datos: boletas (papeletas) entregadas, las no utilizadas, las utilizadas, votos nulos, votos válidos, etc. El software empleado realiza un chequeo continuo de todas las sumas, de modo que, si existen inconsistencias aritméticas, las detecta y las comunica. Los funcionarios del cNc revisan las sumas y analizan la inconsistencia, de modo que si el error no es imputable a los sistemas del Cnc, sino que procede de la propia JRv, no se corrige, sino que se comunica a los fiscales. 
- El departamento de verificación realiza una nueva captura de datos totalmente independiente, en cuyo proceso se lleva a cabo una verificación paralela: si los datos no coinciden con los de la primera captura, el programa avisa, sin precisar dónde está el error (para evitar correcciones ad hoc); se chequean de nuevo los datos para determinar si la incongruencia se debe a un error en este paso del proceso, en cuyo caso se corrige, o, en caso contrario, los datos se pasan al departamento de control de calidad.

- Normalmente no se acude a este paso de control de calidad, sino sólo cuando se han detectado incongruencias entre los datos capturados en los pasos primero y segundo. Por ejemplo, un error típico podría ser que el software detectara en el proceso de verificación que en una JRV han votado más de 400 electores, mientras que en el proceso de recepción el recuento de electores de esa junta no superase el máximo legal. Una vez en el departamento de control de la calidad, si de las comprobaciones practicadas resultase que los datos cuadran, entonces ya estarían listos para su archivo y para ser comunicados a los fiscales. En ningún proceso electoral anterior ha sucedido que haya persistido la incongruencia sin que el departamento de control de calidad haya podido determinar qué captura de datos, la primera o la segunda, era la acertada.

- Por último, se produce la fase de archivo de los datos escrutados. Es muy importante destacar que, además de este archivo definitivo, en cada uno de los pasos que siguen los datos desde su recepción se hace un nuevo registro, una copia, es decir, no se destruyen por solapamiento los datos de las fases anteriores a lo largo del proceso. Por otra parte, estos archivos sucesivos posibilitan que se pueda seguir el iter completo de cada acta, paso a paso, sabiendo qué operador manejó los datos en cada momento, de manera que el proceso es transparente y los datos están preparados para cualquier auditoría.

En relación con la comunicación de los datos capturados a los fiscales, éstos reciben las actas una vez escrutadas en tiempo casi real: con un minuto de diferencia. Los fiscales tienen la llamada "opción histórica": el sistema, cada media hora, saca una imagen de los datos, de modo que no se pueden modificar estos datos así fotografiados. Esto significa que un fiscal puede checar cómo estaba el acta a las 7:00, a las 7:30, a las 8:00 y así sucesivamente. Además, a los fiscales periódicamente se les entrega un dossier con datos agregados por municipios, por departamentos y a nivel nacional. 


\section{El MOMENTO PREELECTORAL}

\subsection{Candidaturas y campaña electoral}

Con carácter previo hay que apuntar que los partidos que tenían representación parlamentaria en la Asamblea Nacional en las elecciones anteriores fueron: el Partido Liberal Constitucionalista, con 41 diputados, el Frente Sandinista de Liberación Nacional, con 39 diputados, Alianza Liberal Nicaragüense (ALN), con nueve escaños, y Alternativa por el Cambio (AC), con un diputado.

A estas elecciones de 2006 se presentaron cinco partidos políticos: los cuatro mencionados anteriormente, es decir: PLC, FSLN, ALN y AC, más un nuevo partido, resultado de una escisión del Frente Sandinista: el Movimiento de Renovación Sandinista (MRS). Los candidatos a presidente y vicepresidente de la República presentados a las presidenciales por cada uno de estos partidos eran los que se muestran en la tabla 3:

TABLA 3: Candidaturas a presidente y vicepresidente de la República

\begin{tabular}{|c|c|c|}
\hline Partido & Presidente & Vicepresidente \\
\hline PLC & José Rizo & José Antonio Alvarado \\
\hline FSLN & Daniel Ortega & Jaime Morales Carazo \\
\hline ALN & Eduardo Montealegre & Fabricio Octavio Cajina \\
\hline $\mathrm{AC}$ & Edén Pastora & Mercedes Tenorio \\
\hline MRS & Edmundo Jarquín & Carlos Mejía Godoy \\
\hline
\end{tabular}

La campaña electoral estuvo presidida por la estrategia del miedo orquestada por los oponentes al FSLN. Los recuerdos de la guerra que se llevó a cabo durante el régimen sandinista entre 1979-1990, y de los 50,000 jóvenes que murieron en ese periodo de defensa de la Revolución, fue el lema principal de la ALn de Montealegre. Esta orientación fue respaldada masivamente por los medios de comunicación, que no paraban de proyectar imágenes de mujeres llorando la muerte de sus hijos en el campo de batalla contra unidades militares del ejército constituido y abastecido por los Estados Unidos. 
En mi calidad de observador electoral, pude constatar el ambiente de intoxicación desinformativa que se vivía en los medios en los días anteriores a las elecciones. Como comentaremos enseguida, el respeto del silencio electoral impide que los partidos en lid acudan a los medios de comunicación en los tres días previos a la votación; sin embargo, y además de otras vulneraciones más flagrantes, las televisiones y las emisoras de radio recibían sospechosamente continuas llamadas de espectadores que repetían una y otra vez las mismas consignas, del tipo: "la victoria del Frente supondría otra vez el servicio militar obligatorio", "se llevarán a nuestros hijos a combatir a Irak", "los Estados Unidos y toda la comunidad internacional nos darán las espalda", "los inversores internacionales huirán de Nicaragua y la economía se desplomará”, etcétera.

Ortega, que gobernó el país entre 1979 y 1990, primero como miembro de una junta revolucionaria tras el derrocamiento de la dictadura somocista, y luego como presidente elegido democráticamente en 1985, disputa por tercera vez la presidencia desde 1990, cuando fue derrotado por Violeta Chamorro. Luego perdió en 1996 con Arnoldo Alemán, ahora condenado a 20 años de prisión por corrupción, y en 2001 ante el actual mandatario Enrique Bolaños. Durante el gobierno de Daniel Ortega, Washington aplicó un embargo comercial a Nicaragua y financió a las guerrillas contrarrevolucionarias, "la contra", que intentaron derrocar por las armas al régimen sandinista. Diez años de guerra civil dejaron más de 50,000 muertos y miles de millones de dólares en pérdidas económicas. Precisamente el miedo a la guerra y al desastre económico es lo que excitaron sus contendientes a lo largo de toda la campaña.

Como respuesta a la estrategia de crispación y miedo protagonizada por sus oponentes, la desarrollada por el FSLN, cuya jefa de campaña, Rosario Murillo, era la esposa del candidato presidencial, fue una estrategia de reconciliación nacional, dejando a un lado los mensajes revolucionarios y cualquier viso de radicalidad. Como datos gráficos de lo dicho, cabe destacar el nuevo marketing político del Frente, que abandonó en los símbolos de campaña los tradicionales colores rojo y negro, de modo que las camisetas, las gorras, etc., eran de color fucsia. Asimismo, la canción de la campaña del FsLn era una versión en español de la canción de John Lennon "Give peace a chance", cuyo estribillo repetía insistentemente mensajes de paz y reconciliación. También incluía estrofas recitadas a ritmo de hip-hop destinadas a captar el voto de la nueva generación de jóvenes, que no recuerdan la guerra, ni recuerdan la época que gobernó Ortega; en 
consecuencia no eran presa fácil de la política del miedo. Hay que tener en cuenta que, de los 5.2 millones de nicaragüenses, las tres cuartas partes son menores de 30 años; además, aproximadamente la mitad del padrón electoral, está integrado por personas en edades comprendidas entre los $16^{7}$ y los 30 años, segmento poblacional desatendido por las políticas de los gobiernos anteriores.

Pero la estética de campaña y el marketing electoral del Frente fueron solamente la punta del iceberg de la reubicación de éste, en su discurso y en posiciones políticas concretas, en su afán de sacar a los electores del miedo y la desconfianza. La nueva estrategia asumía la necesidad de simbolizar con transacciones reales la solidez del cambio, con ello, presumiblemente, se evitaría que la intensificación final de la campaña del descrédito y el miedo, como en elecciones precedentes, transformara la victoria en las encuestas en derrota en las urnas. Esta estrategia ha tenido dos planos destacados: el económico y el religioso.

En el plano económico, el gesto más claro fue la elección de Jaime Morales Carazo como candidato a vicepresidente, frente a la elección de un sandinista histórico. Jaime Morales es un banquero y empresario bien valorado por posiciones liberales, que procede del mundo financiero y no tiene ninguna tradición sandinista. Junto con su elección se enfatizó que, de ganar las elecciones, sería el encargado de coordinar toda el área económica del gobierno.

Respecto a las señales al voto conservador y al lobby católico, destacó la participación determinante del FSLN en la aprobación de la ley que elimina el aborto terapéutico, vigente desde hace más de cien años en la legislación nicaragüense. Dicha ley, que prohíbe el aborto bajo cualquier circunstancia al eliminar el artículo 165 del Código Penal, fue aprobada con los votos de todos los grupos parlamentarios excepto los de los diputados del MRs (parte de la bandada del FSLN), por lo tanto también con los votos sandinistas. Dicha aprobación, que se produjo el 26 de octubre, a punto de acabar la legislatura y en plena campaña electoral, no solamente demuestra el giro ideológico del Frente sino la estrategia electoral de concesión a los poderes fácticos durante el periodo más sensible de la larga carrera electoral. Este voto granjeó a Ortega el apoyo de la Iglesia, manifestado explícitamente tanto por el cardenal Obando y Bravo, único cardenal nicaragüense de la iglesia católica, como por el arzobispo de Managua, Leopoldo Brenes.

${ }^{7}$ En Nicaragua se adquiere el derecho de sufragio activo al cumplir los 16 años (Art. 47 Constitución). 


\subsection{Las encuestas preelectorales}

TABLA 4: Tendencias electorales en Nicaragua 2006

(candidato a presidente)

\begin{tabular}{|l|c|c|c|c|c|c|}
\hline $\begin{array}{c}\text { Partidos y } \\
\text { coaliciones }\end{array}$ & $\begin{array}{c}\text { Borge \&t } \\
\text { Asociados } \\
4 / 8 / 06\end{array}$ & $\begin{array}{c}\text { Cid-Gallup } \\
29 / 8 / 06\end{array}$ & $\begin{array}{c}\text { Borge \& } \\
\text { Asociados } \\
24 / 10 / 06\end{array}$ & $\begin{array}{c}\text { Cid-Gallup } \\
26 / 10 / 06\end{array}$ & $\begin{array}{c}\text { Borge \&t } \\
\text { Asociados } \\
27 / 10 / 06\end{array}$ & Promedio \\
\hline FSLN/Ortega & $31.40 \%$ & $29.00 \%$ & $30.00 \%$ & $33.00 \%$ & $34.40 \%$ & $31.56 \%$ \\
\hline $\begin{array}{l}\text { ALN/ } \\
\text { Montealegre }\end{array}$ & $29.10 \%$ & $23.00 \%$ & $22.40 \%$ & $22.00 \%$ & $23.40 \%$ & $23.98 \%$ \\
\hline PLC/ Rizo & $15.70 \%$ & $14.00 \%$ & $14.60 \%$ & $17.00 \%$ & $19.30 \%$ & $16.12 \%$ \\
\hline MRS/Jarquín & $15.20 \%$ & $14.00 \%$ & $10.10 \%$ & $13.00 \%$ & $10.50 \%$ & $12.56 \%$ \\
\hline AC/Pastora & $1.10 \%$ & $1.00 \%$ & $0.40 \%$ & $1.00 \%$ & $0.80 \%$ & $0.86 \%$ \\
\hline
\end{tabular}

Fuente: Elaboración propia.

En la tabla 4 se muestra un esquema de los resultados de las encuestas realizadas por dos empresas privadas, Borge y Asociados, y Cid Et Gallup, entre agosto y octubre de este año. De ellas, así como de las demás encuestas que se divulgaban en las jornadas previas a las elecciones, se podían extraer como conclusiones: $1^{\text {a) }}$ que el candidato del FsLN lideraba indiscutiblemente las encuestas de intención de voto, manteniendo en todo momento un porcentaje superior al 30\% o, en todo caso, con una diferencia de al menos 6 puntos porcentuales respecto a su oponente más próximo; $2^{\text {a) }}$ que Montealegre experimentaba una tendencia a la baja entre agosto y octubre, en las encuestas reflejadas en la tabla 3 pasó del $29.10 \%$ en agosto a $23.00 \%$ en octubre; $3^{\text {a) }}$ que el candidato del PLc, Rizo, presentaba una tendencia irregular, pero al alza; y 4a) que los candidatos de AC y MRS mantuvieron una tendencia a la baja.

Los resultados de estas consultoras, sin embargo, dejaban dudas en relación con la necesidad de celebración de una segunda vuelta. La duda se debía al alto porcentaje de indecisos, entre el $8 \%$ y el 9\%, cuya decisión sin duda iba a ser determinante, no tanto en el resultado en primera vuelta como en el porcentaje de votos con que Ortega la ganaría. Por tanto, quedaba sin resolver la determinante cuestión de saber si ganaría en primera vuelta, si los votos de los indecisos se decantaban por él, como 
parece que finalmente sucedió, o, por el contrario, determinar una segunda vuelta, si esos votos se canalizaban hacia el Mrs, en caso de que fueran votos de castigo. Y todo ello sin valorar el posible abstencionismo elevado, probabilidad que sin embargo no se confirmó, puesto que la participación ciudadana fue muy elevada, superior al 61\%.

En cuanto a la distribución geográfica de la intención de voto, según la encuesta de la consultora M \& R efectuada entre los días 19 y 22 de octubre, realizada a nivel nacional con datos desagregados por zonas, los resultados son los que se indican en la tabla 4:

TABLA 5: Distribución geográfica de la intención de voto

\begin{tabular}{|l|c|c|c|c|c|c|}
\hline & FSLN & ALN & PLC & MRS & AC & Indecisos \\
\hline Zona metropolitana & $28.8 \%$ & $21.3 \%$ & $15.2 \%$ & $25.3 \%$ & 0.5 & 8.8 \\
\hline Zona urbana & $31.6 \%$ & $26.0 \%$ & $14.5 \%$ & $19.0 \%$ & 0.6 & 8.3 \\
\hline Zona semirrural & $36.1 \%$ & $26.9 \%$ & $19.2 \%$ & $9.1 \%$ & 0.3 & 8.3 \\
\hline Zona rural & $36.8 \%$ & $22.9 \%$ & $22.2 \%$ & $8.9 \%$ & 1.0 & 9.2 \\
\hline Total general & $33.8 \%$ & $25.4 \%$ & $17.1 \%$ & $14.8 \%$ & 0.6 & 8.2 \\
\hline
\end{tabular}

Fuente: Elaboración propia a partir de los datos de la encuesta de M\&t.

Tales resultados sugerían que: $1^{\circ}$ ) el FSLN tenía su mayor cuenca de votos en las zonas metropolitana, semirrural y rural, donde supera ampliamente al ALN; $2^{\circ}$ ALN tenía una buena intención de voto en la zona metropolitana; $3^{\circ}$ ) el PLc tenía su mayor caudal de intención de voto en el área rural, situación que quedó evidenciada en las elecciones regionales de Nicaragua, efectuadas el 5 de marzo, donde logró 36,891 votos; el FSLN 25,190; YATAMA 14,938; ALN 8,520; y MRS 2,675 votos, entre otros participantes.

El 1 de noviembre se dieron a conocer los resultados de otra encuesta, realizada por la UCA (Universidad Católica de Managua, universidad jesuita), el Nuevo Diario, Canal 10 y la Cámara de Comercio de Nicaragua, es decir, cuatro entidades con intereses distintos y sin filiaciones partidistas, lo que la hacía particularmente creíble para la opinión pública. Según esta encuesta de intención de votos urbanos y semirrurales, el Frente Sandinista resultaría ganador en primera vuelta. Los principales sesgos de esta encuesta eran, en primer lugar, el porcentaje de indecisos, que alcanzaba el 12\%, lo cual podía inclinar la balanza a favor de cualquiera de los tres grandes partidos en contienda; $y$, en segundo lugar, por el hecho de no medir el voto plenamente rural, donde tradicionalmente 
el Partido Liberal Constitucionalista basa su fortaleza y podía seguir captando votos a pesar del desgaste de cinco años de gobierno. (De hecho, durante los dos primeros días que siguieron a la votación, el PLC se resistió a aceptar los resultados preliminares que concedían la victoria al FSLN, amparándose en que los votos pendientes de recuento eran, precisamente, los de las zonas rurales, y alertando de que venía en camino "el tsunami rojo", refiriéndose al aluvión de votos rurales al PLC, partido cuyo color es el rojo.)

\subsection{LA VULNERACIÓN DEL SILENCIO ELECTORAL}

El Art. 97 de la Ley Electoral establece tres jornadas de reflexión (en la terminología electoral de España) previas a la votación, o de silencio electoral en su propia terminología. Durante el periodo de silencio electoral los partidos deben cesar toda actividad de la campaña electoral, y también, los medios de comunicación, deben suprimir la propaganda electoral 72 horas antes de las elecciones, limitándose, en su labor informativa con respecto a las votaciones, a difundir la información acerca de los procedimientos para ejercer el derecho del sufragio.

Sin embargo, varios medios de comunicación infringieron el periodo de silencio electoral, emitiendo canciones de campaña (Canal 4 y La Nueva Radio Ya), tertulias de expertos en los que analistas hicieron campaña a favor de una u otra opción política (Canal 2, Canal 8 y Canal 10), y publicando artículos de opinión claramente a favor de una opción política ( $\mathrm{La}$ Prensa y El Nuevo Diario).

Como tendremos ocasión de reiterar más adelante, al analizar la labor de las distintas Misiones de Observación Electoral (en adelante, MOE), la infracción del silencio electoral ha sido una de las críticas más resaltadas por los observadores, especialmente internacionales.

\subsection{LA INJERENCIA EXTRANJERA}

Junto con la quiebra del silencio electoral, la injerencia extranjera ha sido la segunda nota negativa que las Misiones de Observación Electoral se manifestaron con más énfasis respecto de este proceso electoral. En efecto, la campaña electoral, que despertó un enorme interés a nivel internacional, se vio afectada por injerencias y presiones externas, que conculcan el principio de soberanía nacional. 
Por una parte, el candidato de ALn, Montealegre, quien ha sido acusado de estar apoyado por los Estados Unidos, donde ha vivido siempre hasta que se afıncó en Nicaragua hace siete años, denunció que Hugo Chávez estaba inmiscuyéndose en el proceso electoral nicaragüense "usando los recursos del petróleo para influenciar y hasta comprar la voluntad de los nicaragüenses a favor de Daniel Ortega", y que "Chávez está regalando el $30 \%$ de la urea (fertilizante) que consume este país en un periodo de cuatro meses para distribuirla y regalarla a través de alcaldías sandinistas".

Pero lo que es indiscutible es la intervención en la campaña de funcionarios del Departamento de Estado y del Congreso de Estados Unidos, y de la propia Casa Blanca que repitió en diversas ocasiones a lo largo de la campaña un mensaje de amenaza para el caso de que ganase las elecciones el candidato del Frente Sandinista, incluso amenazando con promover un embargo de las remesas de los emigrantes nicaragüenses en Estados Unidos si Ortega resultaba ganador.

El Departamento de Estado, a través del portavoz de Condoleezza Rice, Sean McCormack, declaró el jueves 2 de noviembre que Estados Unidos no trata de "influir en la opinión ni tomar posición" en las elecciones, pero recordó que los cambios en las políticas de sus socios "se toman en cuenta" para la asignación de ayuda exterior.

Por su parte, el embajador estadunidense en Managua, Paul Trivelli, quien mostró a lo largo de la campaña su respaldo pleno a Montealegre, e incluso a Jarquín, del MRS, en una entrevista para la BBC se refirió a la posibilidad de que ganase Ortega en los siguientes términos: "Sería una tragedia para Nicaragua si las elecciones suponen una regresión. Todos los países de Centroamérica se verían afectados, sus avances por el libre comercio y todos los demás avances que han hecho."

Destacaremos, como último ejemplo, la reaparición del coronel retirado estadunidense Oliver North, cabeza operativa del tráfico secreto de armas a Irán implementado por el gobierno de Ronald Reagan (1981-1989) para financiar a "la contra" nicaragüense. North visitó el país con el objetivo de recordar a los ex-contras contra quién debían enfocar su participación electoral, se entrevistó personalmente con el candidato del PLc, José Rizo, y declaró que el triunfo del sandinismo "sería lo peor para Nicaragua". 


\section{LA JORNADA ELECTORAL}

\subsection{Transcurso de la JoRnada electoral}

La participación fue masiva y las votaciones se desarrollaron en un ambiente de tranquilidad, sin que se registraran incidentes que pudieran indicar que hubiese condicionantes o interferencias en el libre ejercicio el derecho al sufragio activo. Se constató la presencia en todas las mesas de fiscales de los cinco partidos que se presentaban a las elecciones; el respeto a los procedimientos establecidos para el ejercicio correcto del sufragio; y el respeto al secreto del voto, que se garantizó mediante cabinas portátiles en cada JVR. Hay que destacar también la ayuda recibida por las personas discapacitadas para facilitarles su derecho al voto, a través de voluntarios en todos los centros electorales visitados. Asimismo, la tranquilidad del proceso se veía reforzada por la presencia del llamado "policía electoral", que eran los encargados de la seguridad en cada una de las mesas y que estaba compuesta igualmente por voluntarios.

Los ciudadanos nicaragüenses, como ya se ha señalado, votaban en estas elecciones presidenciales y legislativas de 2006: presidente y vicepresidente, para lo cual se empleaba una papeleta con una franja de color azul; diputados en carácter nacional, a los que les correspondía una papeleta con franja color café; diputados por circunscripción departamental o regional, en cuyo caso la franja era de color gris; y por último, diputados al Parlacén (franja negra). Esta multiplicidad de papeletas, así como la afinidad de colores de algunas de ellas, ralentizaba el proceso de votación.

Otro elemento que redundaba en el lento desarrollo de las votaciones era la identificación de los electores. La comprobación de la identidad de los electores en las Juntas Receptoras de Votos se hacía mediante padrón fotográfico, elaborado y remitido por el CSE a partir de las cédulas de identidad.

El padrón contiene: el número de la Cédula, el nombre y apellidos a favor de quien se expide, el sexo, la dirección de su domicilio, la fecha de expedición de la Cédula y la fecha de expiración (Art. 32, Ley Electoral). La inscripción de un ciudadano en el padrón se realiza automáticamente en el momento de expedición de su cédula de identidad, asignándole la JRV que le corresponde en función de su domicilio. En caso de cambio de domicilio, se debe solicitar el procedimiento de reposición de la Cédula en el Registro Civil del CSE, para que se le otorgue una cédula con la nueva 
dirección. Según establece el Art. 41 de la Ley Electoral, si un votante no encuentra su nombre en el padrón de la mesa correspondiente a su domicilio habitual, pero tiene su cédula de identidad correctamente expedida que prueba su residencia, la JRV es competente para autorizarle a emitir su voto, haciéndolo constar como incidencia en el acta.

Como ya se ha señalado anteriormente, el padrón electoral definitivo ascendía a 3,665,141 votantes, de lo cuales ejercieron su derecho el día 5 de noviembre un total de 2,224,215 nicaragüenses. En cuanto al cierre $\mathrm{y}$ recuento de las papeletas, se desarrollaron sin incidentes y de forma pacífica, aunque también muy lentamente, debido en buena medida a la confusión que provocaban, por su similitud, los colores de las cuatro papeletas.

La lentitud fue también la nota que marcó la presentación de los informes con los datos preliminares del escrutinio por parte del CSE. Así, el primer informe no tuvo lugar hasta la 1:30 de la madrugada, ya del día 6 de noviembre (siendo la jornada el 5 de noviembre), todavía con sólo el 2.8\% de las JRV escrutadas. De hecho, los resultados definitivos con el 100\% de las JRV escrutadas no se hicieron públicos hasta el 14 de noviembre, y la proclamación de electos por el CSE de los hasta entonces candidatos a la presidencia y vicepresidencia tuvo lugar el 22 de noviembre.

\subsection{LOS OBSERVADORES ELECTORALES}

Estas elecciones presidenciales y legislativas de Nicaragua 2006 han sido calificadas por los medios de comunicación como las elecciones más observadas, con más de 13,000 observadores nacionales y alrededor de mil internacionales. No es de extrañar, dado el interés que suscitaban tanto dentro como fuera del país, debido a que las encuestas daban como ganador a Daniel Ortega 16 años después, y al clima de tensión creado por los candidatos liberales durante toda la campaña.

Respecto de la observación nacional, es necesario destacar la movilización de las fuerzas liberales y conservadoras del país en la articulación de misiones de observación o en el apoyo legitimatorio de las existentes. Sensu contrario, destaca la ausencia de estrategia del Frente y de posiciones progresistas en el mismo ámbito. Todo indicaba que, de producirse un resultado ajustado, la observación nacional mayoritaria hubiera defendido las posiciones liberales.

Desde todos los puntos de vista la organización Ética y Transparen- 
cia (www.eyt.org.ni/) fue la misión nacional más importante. Con 11,200 observadores desplegados por todo el territorio del país, conseguía tener prácticamente un observador en cada mesa (recordemos que en total había 11,274 JRV, ver tabla 1). Esta organización, filial nicaragüense de Transparency International (http://www.transparency.org/), desarrolló su propio sistema de conteo rápido, en paralelo al oficial del CSE, pero sin haber remitido a este órgano las reglas y metodología del recuento que iban a realizar. Los resultados de este escrutinio extraoficial acabaron por ser la avanzadilla de los resultados oficiales, coincidiendo en todas las tendencias con los finalmente proporcionados por el CSE. No es de extrañar su grado de acierto, dada la abundancia de observadores con que contaban, ni tampoco que su recuento fuera mucho más rápido que el oficial, al estar exento de todos los filtros y verificaciones con que cuenta el sistema de escrutinio realizado en el Centro Nacional de Cómputos, tal como se ha explicado anteriormente.

Junto a Ética y Transparencia, otras organizaciones nacionales tuvieron una presencia significativa en los comicios: el Instituto para el Desarrollo y la Democracia, Ipade (http://www.ipade.org.ni/), el Movimiento por Nicaragua (http://www.mpn.org.ni/), Hagamos Democracia (http://www. hagamosdemocracia.org/) y el Consejo Nacional de Universidades, cnu (http://www.cnu.edu.ni/), que también realizó su propio conteo rápido pero, a diferencia de Ética y Transparencia, sí remitió su metodología de recuento al CSE; y, a pesar de ello, se abstuvo de dar resultados con carácter previo a los oficiales tal y como requirió la autoridad electoral.

Respecto de la observación internacional, es de destacar la constatación del cambio lento que se venía experimentando en los procesos electorales precedentes, y que puede resumirse en una pérdida de la capacidad de injerencia de los Estados Unidos provocada, en buena medida, por la consolidación de la observación electoral internacional plural. Lo cual ha sido particularmente llamativo por la creación de una misión específica dirigida por el gobierno de Estados Unidos desde su embajada, y el aislamiento absoluto de la misma a la hora de valorar el proceso como poco confiable.

En cuanto a la Misión de Observación Electoral de la Organización de los Estados Americanos, ofA (www.oas.org/), con 183 observadores desplegados, debe enfatizarse que fue la primera misión que reconoció la limpieza de los resultado (11:00 horas del día 6 de noviembre), en concreto a través del jefe de la misión, Gustavo Fernández, quien declaró que la votación había sido "pacífica, masiva, ordenada y ajustada a la ley". En el 
mismo sentido, el actual presidente de la OEA, José Miguel Insulza, declaró desde la reunión de la Internacional Socialista que se celebraba en las mismas fechas en Santiago de Chile, que estaba satisfecho con el desarrollo de la votación.

Es de destacar igualmente la labor realizada por la Misión de Observación Electoral de la Unión Europea (http://www.eueom-nic.org/report es?idsubseccion=15), con 150 observadores desplegados, por su claridad en la valoración de las elecciones y en la denuncia de la injerencia de los Estados Unidos en el proceso electoral nicaragüense. En su primera comunicación el día siguiente de las elecciones, el jefe de la misión (primera intervención 17:30 horas del día 6 de noviembre) destacó la actitud pacífica del pueblo nicaragüense durante las votaciones y el formidable papel de la sociedad civil nicaragüense, resaltando el elevado índice de participación como indicador de su compromiso con la democracia; criticó la falta de contenidos políticos de la campaña electoral, que estuvo llena de descalificaciones personales; resaltó la lentitud en el suministro de datos oficiales del escrutinio; denunció el elevado grado de politización del CSE a favor de los dos partidos históricos; y, como ya hemos dicho, destacó la injerencia de actores extranjeros durante la campaña, manifestación que llegó a concretar apuntando expresamente a los Estados Unidos.

Por último, es preciso referirse a la actuación llevada a cabo por la Misión de Observación Electoral del Centro Carter, centro sobre el que planean ciertas sospechas de influenciabilidad estadunidense. En Nicaragua el Centro Carter se presentó con un perfil más alto de lo habitual, incluyendo en su delegación junto al expresidente de Estados Unidos, Jimmy Carter, al expresidente peruano Alejandro Toledo y al expresidente de Panamá, Nicolás Ardito Barletta. A la sazón, y como viene siendo habitual, el cuerpo de su delegación estaba compuesto por una mayoría de miembros no cualificados en materia electoral. El papel relevante de la misión se manifestó antes, durante y en el mismo día de las votaciones; Carter solicitó entrevistas con todos los candidatos, pero precisamente el mismo día de las votaciones por la mañana, con siete horas hasta el cierre de los colegios electorales, Carter se entrevistó con el candidato liberal de la ALn, Montealegre, apareciendo conjuntamente en público ante todos los medios de comunicación. En lo referente a la valoración de su actuación específica como misión de observación, cabe resaltar que durante los días previos a la votación no cesaron de hacer declaraciones haciendo saltar falsas alarmas sobre la limpieza del proceso electoral y poniendo de manifiesto su 
preocupación ante supuestas fallas democráticas que iban a comprometer seriamente los resultados. Finalmente, y ante las innegables condiciones de limpieza y tranquilidad con que transcurrió la jornada electoral, el Centro Carter en sus informes poselectorales no tendría más remedio que declarar su conformidad con el proceso electoral y su aceptación de los resultados (www.cartercenter.org/).

\section{Gráfico 1: Presidente y Vicepresidente}

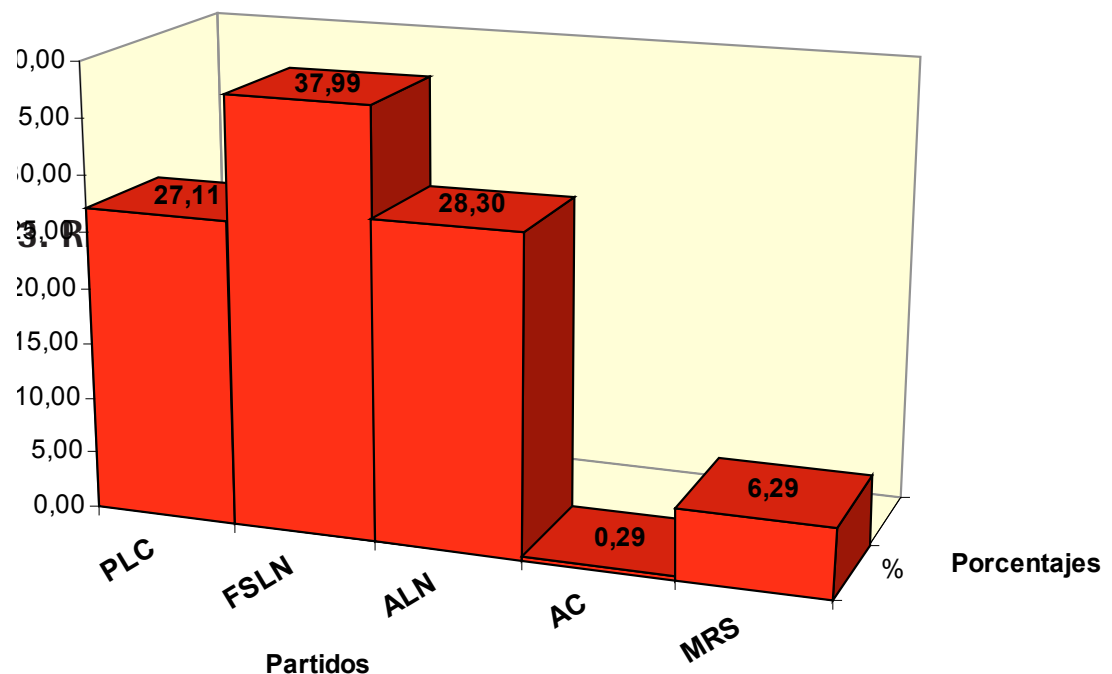

Fuente: Elaboración propia a partir de los datos oficiales del cSE, con el 100\% de las Juntas Receptoras de Votos escrutadas, 27/11/06. 
Gráfico 2: Diputados Nacionales

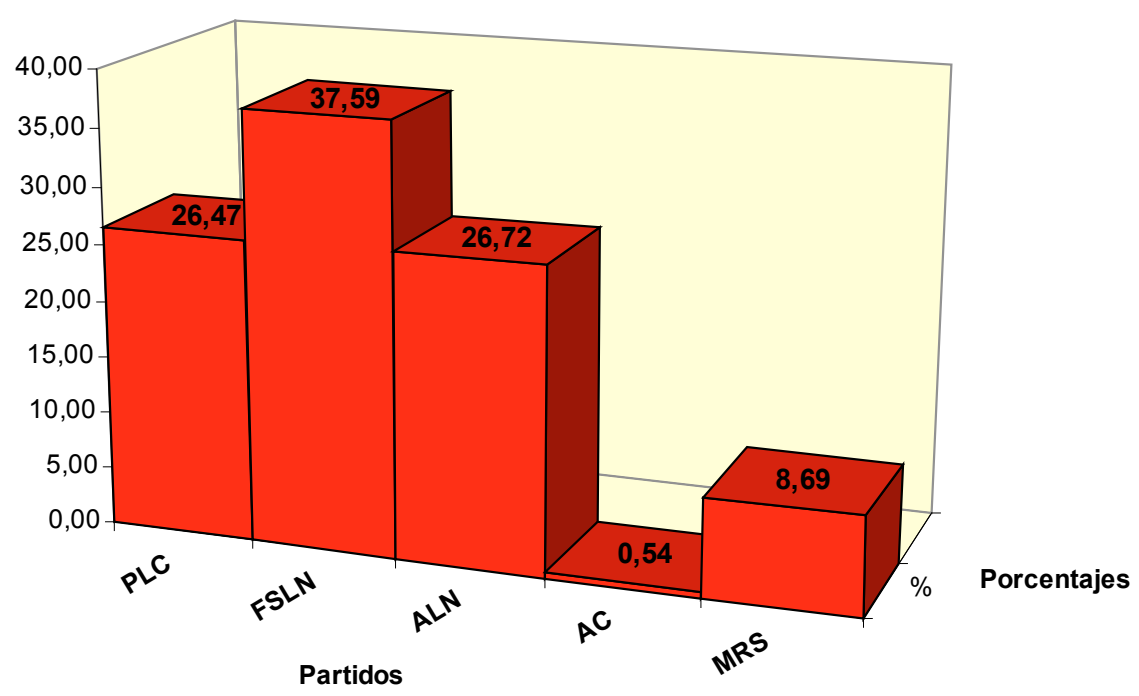

Fuente: Elaboración propia a partir de los datos oficiales del CSE, con un 100\% de las Juntas Receptoras de Votos escrutadas (últimos datos proporcionados en el website del CSE, 27/11/06).

\section{Gráfico 3: Diputados Departamentales}

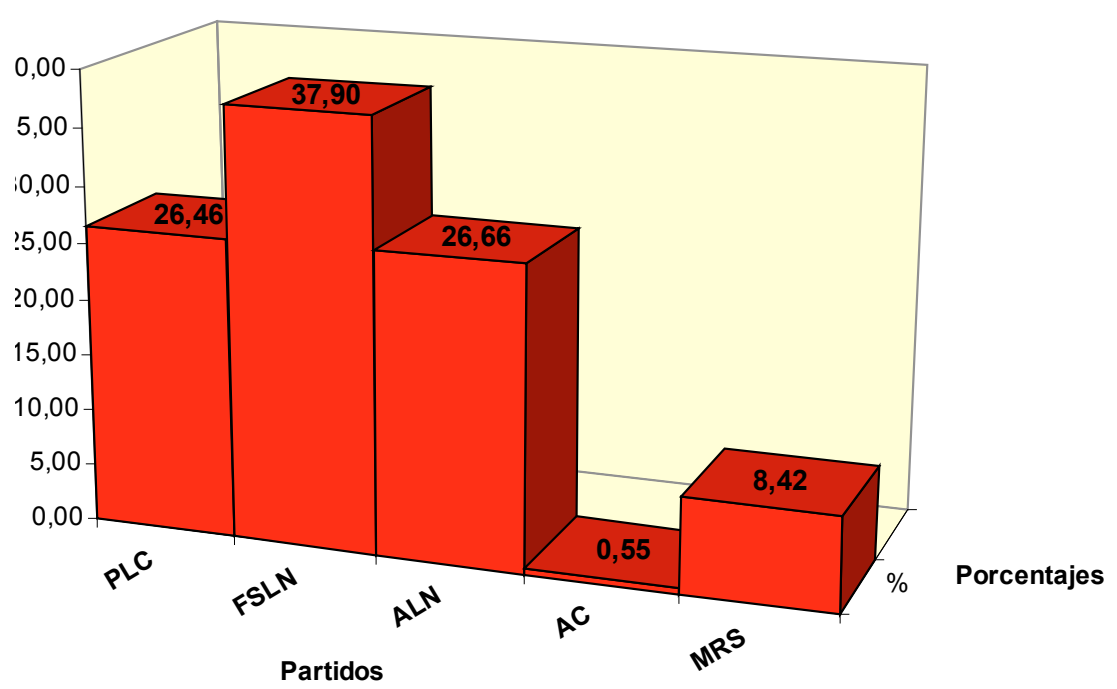

Fuente: Elaboración propia a partir de los datos oficiales del CSE, con un 100\% de las Juntas Receptoras de Votos escrutadas (últimos datos proporcionados en el website del cSE, 27/11/06). 


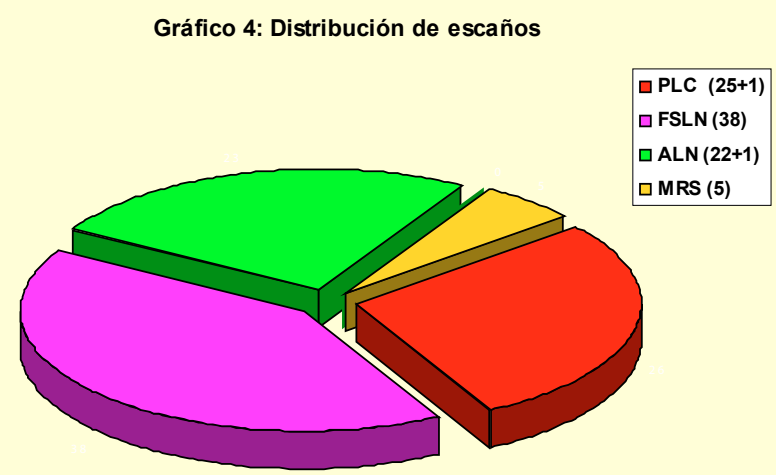

Fuente: Elaboración propia a partir de las informaciones del CSE, con el 100\% de las JRV escrutadas.

\section{Gráfico 5: Diputados Parlamento Centroamericano}

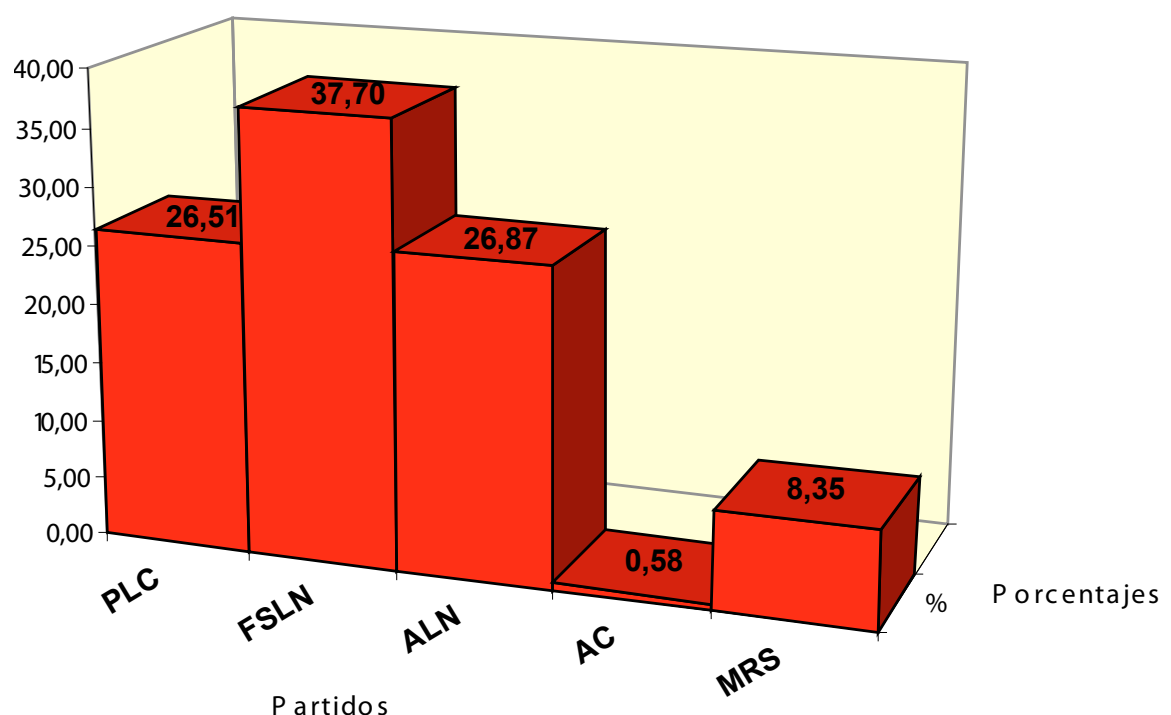

Fuente: Elaboración propia a partir de los datos oficiales del cse, con un 100\% de las Juntas Receptoras de Votos escrutadas (últimos datos proporcionados en el website del cSE, 27/11/06). 


\section{INTERPRETACIÓN DE LOS RESULtAdOS ELECTORALES}

\subsection{Elecciones a la presidencia y Vicepresidencia de la República}

Para una mejor comprensión de las elecciones a la Presidencia y Vicepresidencia de la República, debemos considerar al pacto constitucional realizado en el año 2000 entre el entonces presidente, Arnoldo Alemán, del Partido Liberal Constitucional y el FsLN, por el cual distribuyeron la presencia bipartidista en los poderes del Estado, pacto que se formalizó mediante una reforma constitucional. Fruto de aquel pacto, entre otros, fue la reforma de la normativa electoral, por la que un candidato presidencial puede ganar las elecciones en una primera vuelta en dos casos: a) si obtiene más del 40\% de los votos; b) si consigue el 35\% con una diferencia de cinco puntos porcentuales sobre el segundo más votado. ${ }^{8}$

Como se observa en el gráfico 1, el expresidente y candidato del Frente Sandinista de Liberación Nacional obtuvo más del 35\% de los votos (37.99\%); y su principal contrincante, Eduardo Montealegre, de la Alianza Liberal Nicaragüense (ALN), menos del 30\% (28.30\%); en consecuencia, la diferencia entre ambos candidatos (9.69\%) fue suficiente para que el FSLN se alzase con la victoria en una primera vuelta.

Antes de la predicha reforma, la victoria en primera vuelta se obtenía con el 45\% de los votos. Para la mayoría mediática, en 2000 y ahora, esa reforma estaba hecha a la medida de Ortega, quien había sido incapaz de vencer en dos elecciones presidenciales sucesivas, perdiendo ambas a manos de los liberales. Sin embargo, la reforma no le sirvió para ganar las elecciones de 2001, en las que fue rotundamente derrotado por Enrique Bolaños, del Partido Liberal Constitucional. Así, Daniel Ortega se presentó a las elecciones de 2006 tras tres derrotas consecutivas en otras tantas elecciones presidenciales (1990, 1996 y 2001).

A la luz de estos datos y desde la estricta perspectiva cuantitativa electoral, el candidato del partido liberal tradicional, José Rizo, y el candidato del nuevo partido liberal, Eduardo Montealegre obtuvieron el 55.41\% (27.11\% + 28.30\%);

\footnotetext{
${ }^{8}$ Constitución de Nicaragua, Art. 147: "Para ser elegidos Presidente y Vicepresidente de la República los candidatos a tales cargos deberán obtener como mayoría relativa al menos el cuarenta por ciento de los votos válidos, salvo el caso de aquellos que habiendo obtenido un mínimo del treinta y cinco por ciento de los votos válidos superen a los candidatos que obtuvieron el segundo lugar por una diferencia mínima de cinco puntos porcentuales. Si ninguno de los candidatos alcanzare el porcentaje para ser electo, se realizará una segunda elección únicamente entre los candidatos que hubiesen obtenido el primero y segundo lugar y serán electos los que obtengan el mayor número de votos."
} 
por su parte, si sumamos los votos del FSLN junto con los del candidato de la escisión sandinista Edmundo Jarquín (del Movimiento Renovador Sandinista) obtuvieron el 44.28\% (37.99\% + 6.29\%). Sin embargo, un análisis cualitativo de la formación de las distintas candidaturas y el desarrollo de la campaña, imposibilita considerar que la presencia de una candidatura por segmento ideológico hubiese sido posible; igualmente imposibilita creer que, de haberse producido, el sumatorio hubiese sido equivalente al conseguido por separado.

Efectivamente, la escisión sandinista se produce después de que el FSLN y el MRS hubiesen concurrido conjuntamente en las dos elecciones presidenciales precedentes, siendo elementos consustanciales las deserciones y expulsiones de miembros históricos del Frente, con trasvase hacia el MRS, parte determinante en la opción electoral. Igualmente, ha resultado determinante en la configuración del escenario electoral la estrategia determinada del MRS durante la campaña de obtener votos exclusivamente sobre el desgaste del Frente: apelando a la corrupción histórica y presente del Frente en la reforma, al corrimiento desde posicionamientos tradicionales hacia el pragmatismo electoral, así como al entendimiento con los liberales desde la reforma de 2000.

En el lado liberal, el surgimiento del liderazgo de Montealegre ha provocado la emergencia como segunda fuerza del país de un movimiento previamente inexistente: la Alianza Liberal Nicaragüense. Dicho candidato, por el que apostó decididamente Estados Unidos, consiguió entender y capitalizar la crisis del PLc. Esta crisis en buena medida trae causa del lastre de la mala gestión y corrupción de la administración de Arnoldo Alemán (1996-2001), la cual se manifestó en su máximo esplendor durante la legislatura anterior, llevando al propio líder a ser condenado (actualmente cumple una condena de 20 años de prisión en régimen de arresto domiciliario por diversos actos de corrupción y tiene abierto un proceso en Panamá - que se encuentra en estado bastante avanzado- por blanqueo de dinero). El estado de desaliento del PLc hizo que los intereses económicos nacionales y los político-económicos estadunidenses inventaran el liderazgo de Montealegre. El miedo a la alternativa del Frente entre el voto conservador y un segmento significativo del moderado, junto con las injerencias -estadunidenses y de poderes económicos nacionales e internacionales- azuzando dichos miedos hicieron el resto. Es necesario recordar, como vimos en su momento, que las injerencias estadunidenses fueron destacadas por el jefe de la misión de observación electoral de la Unión Europea como uno de los aspectos más negativos de la campaña. 
Un último dato a tener en cuenta pro futuro, es la influencia de la reforma del sistema electoral -disminución del umbral de elección del presidente- y constitucional -disminuyendo las competencias residenciadas en la institución- que han coadyuvado en la postulación de candidaturas fuertes, en resultados y en presencia electoral, frente al tradicional bipartidismo.

\subsection{Elecciones a diputadoos de la Asamblea Nacional, en la CIRCUNSCRIPCIÓN NACIONAL Y EN LAS CIRCUNSCRIPCIONES DEPARTAMENTALES Y REGIONES AUTÓNOMAS}

Como explicación previa es necesario tener en cuenta que, de acuerdo con el Art. 132 de la Constitución de Nicaragua, en las elecciones generales se ponen en juego 90 escaños de los 92 que componen la Cámara de Diputados; de esos 90, 20 diputados se eligen en la votación a la Asamblea Nacional y los 70 restantes en las circunscripciones departamentales y regiones autónomas. Los otros dos escaños, según lo dispuesto en el Art. 133, pasan a ocuparlos automáticamente el expresidente del gobierno de la legislatura inmediatamente anterior (Bolaños), y el candidato a presidente de la República en las últimas elecciones que hubiera quedado en segundo lugar (en el caso que nos ocupa, Montealegre, candidato por ALN). ${ }^{9}$

Así, los resultados (ver gráficos 2, 3 y 4) arrojan el siguiente resultado: FSLN $=38 ;$ ALN $=23(22+1$ de Montealegre en su condición de candidato posicionado en segundo lugar); PLC $=26(25+1$ de Bolaños en su condición expresidente de la República); MRS $=5$.

La comparación de los porcentajes de voto entre todas las elecciones disputadas son prácticamente idénticos, no superando en casi ningún caso el medio punto porcentual. La excepción a la regla (ALN), tampoco resulta significativa, ya que simplemente obtuvo más de un punto en las presidenciales (28.30\%) respecto a las legislativas (26.72\% diputados nacionales;

\footnotetext{
${ }_{9}^{9}$ Art. 132 El Poder Legislativo lo ejerce la Asamblea Nacional por delegación y mandato del pueblo. La Asamblea Nacional está integrada por noventa diputados con sus respectivos suplentes elegidos por voto universal, igual, directo, libre y secreto, mediante el sistema de representación proporcional. En carácter nacional, de acuerdo con lo que se establezca en la Ley Electoral, se elegirán veinte diputados, y en las circunscripciones departamentales y regiones autónomas setenta diputados.

Art. 133 También forman parte de la Asamblea Nacional como Diputados, Propietario y Suplente respectivamente, el Ex Presidente de la República y Ex Vicepresidente electos por el voto popular directo en el periodo inmediato anterior, y, como Diputados, Propietario y Suplente los candidatos a Presidente y Vicepresidente de la República que participaron en la elección correspondiente, y hubiesen obtenido el segundo lugar.
} 
26.66\% diputados departamentales). No ha habido pues, voto cruzado ni efecto corrector: ni por la disparidad de sistema electoral, ni de composición de la circunscripción, ni por la dispar utilidad de voto atendiendo a la contienda. Lo dicho es más cierto si cabe en las elecciones a la Asamblea donde los porcentajes a diputados nacionales y a diputados departamentales obtenidos por un solo partido simplemente ofrecen las diferencias centesimales achacables a los votos anulados. La única incidencia destacable del sistema electoral se produce entre los dos partidos liberales; así el tradicional PLc ha obtenido tres escaños más que ALN pese a haber obtenido menos votos ésta (22 escaños; 26.72\% diputados nacionales; $26.66 \%$ diputados departamentales) y PLc (25 escaños; $26,47 \%$ diputados nacionales; $26.46 \%$ diputados departamentales). Dicha disparidad se debe a la combinación del sistema electoral explicado y a la concentración de voto rural del PLc.

En cualquier caso, el resultado de las elecciones a diputados de la Asamblea Nacional, ha estado marcado por la fragmentación parlamentaria. Este mayor fraccionamiento que en elecciones precedentes coincide con el punto álgido en la política de alianzas y control de mayorías parlamentarias, ello debido a la reforma constitucional. Efectivamente la necesidad de establecer alianzas parlamentarias será más importante en la legislatura entrante que en ninguna de las anteriores debido a que el 20 de enero está prevista la entrada en vigor de la reforma constitucional, que debilita sensiblemente el régimen presidencialista fortaleciendo al Parlamento.

Entrando en la política de alianzas parlamentarias, es necesario recordar que la mayoría simple se encuentra en 47 diputados (sobre un total de 92 diputados), y la mayoría cualificada necesaria para las reformas de mayor relevancia constitucional, y para la reforma de la propia Constitución, se sitúa en 56 diputados.

Llegados aquí, los resultados (ver gráficos 2,3 y 4) posibles eran: FSLN $=38 ;$ ALN $=23(22+1$ de Montealegre en su condición de candidato posicionado en segundo lugar); PLC $=26(25+1$ de Bolaños en su condición de expresidente de la República); MRS $=5$.

Las alianzas aritméticas son: FSLN + MRS $=43 ;$ FSLN + PLC $=64 ;$ ALN + PLC $=49 ;$ FSLN + ALN $=61$.

El resultante de estas cifras es que Daniel Ortega necesitaba pactar con los liberales, tanto la política legislativa como la constitucional. Por su parte, los liberales podían marginar al Frente de la política legislativa, gracias al debilitamiento que sufrirá el veto presidencial (vid. infra), hasta extremos nunca conocidos. 
El mayor impedimento para que dicha posibilidad no se lleve a cabo radica en la propia pugna por el liderazgo nacional del lado liberal, liderazgo que, pese a sus llamadas al hermanamiento liberal, pretende Montealegre en su condición de diputado (Rizo, del PLc, ni siquiera será diputado suplente de Bolaños, por resolución del CSE, por haberse postulado candidato a presidente) y candidato más votado a las presidenciales. El Frente puede instrumentalizar los recelos del PLC frente a ALN y a los Estados Unidos por su cambio de apoyos, manteniendo el pacto institucional ya explicado con el PLC.

\subsection{ReLACIONES EXTERIORES Y POLÍTICA ECONÓMICA}

Para comprender la importancia extraordinaria de la política de alianzas parlamentarias y las limitaciones de la victoria del Frente, junto con la reforma constitucional, debemos considerar a las directrices básicas de la política social y económica que están intrínsecamente con las relaciones exteriores respecto a los dos modelos-bloques actualmente desarrollados en Latinoamérica.

Según los informes del Banco Mundial, el 70\% de los nicaragüenses viven con menos de dos dólares al día, y el 35\% está en la extrema miseria con ingresos inferiores a un dólar. Además, el 13\% de la población está en paro, y el 27\% está empleado en el sector informal.

El principal reto de Ortega y su principal compromiso electoral es atender los acuciantes problemas sociales y revertir la realidad que sitúa a Nicaragua como uno de los países más pobres del continente. En esa tarea el vicepresidente económico del Frente, cuyo perfil y antigua adscripción liberal ya hemos visto, considera esencial atraer la inversión privada y generar mayores fuentes de empleo.

La primera reunión del presidente electo, tras conocerse los resultados, fue con inversores extranjeros. El mensaje lanzado allí fue que la nueva administración no pondrá en riesgo la participación del país en el Tratado de Libre Comercio de América Central (CAFTA) con Estados Unidos, con quien pretende tener "relaciones respetuosas". Al mismo tiempo Ortega ha declarado que "un elemento fundamental que tiene que ver con la política de Estados Unidos hacia toda la región es cómo lograr que los norteamericanos correspondan a las decisiones que tenemos los latinoamericanos de establecer relaciones respetuosas en el ámbito político y relaciones justas en el plano comercial y social". Así, formalmente, la propuesta de Ortega 
pretende la cuadratura del círculo - habida cuenta de los últimos acontecimientos en torno al Pacto Andino-Mercosur-: por un lado su deseo de trabajar con el gobierno norteamericano y de respetar el acuerdo comercial CAFTA; pero al mismo tiempo reconociendo que su gobierno fortalecerá relaciones comerciales con países como Venezuela, Bolivia y Cuba.

\section{Reforma constitucional}

Como hemos adelantado, para comprender la importancia extraordinaria de la política de alianzas parlamentarias y las limitaciones de la victoria del Frente Sandinista, debemos considerar el contenido básico de la reforma constitucional que tuvo lugar con carácter previo a las elecciones analizadas. Junto con ella corresponde analizar la propuesta de reforma constitucional que ya se da por hecho cierto pese a estar, al cierre de este artículo, a escasos nueve meses de gobierno.

\subsection{LA REFORMA CONSTITUCIONAL REALIZADA}

La reforma constitucional precedente a las elecciones, esencialmente supuso un reforzamiento de la Asamblea. Daniel Ortega, principal promotor de esta reforma desde la oposición, declaró de forma precipitada tras su elección su intención de mantenerla desde el gobierno, pese a que ello disminuya ostensiblemente sus competencias presidenciales. Con ello ha dado un primer aldabonazo a su política de reconciliación y consenso, a la par que ha desmentido a los medios y líderes que han venido postulando que el FSLN propuso la reforma para estar en la oposición.

Entre los nuevos poderes de la Asamblea destacan:

1. "Ratificar" (Nueva redacción del Art. 138.4 de la Constitución) el nombramiento de los ministros y viceministros de Estado y a otros altos cargos: procurador y subprocurador general de la República, jefes de misiones diplomáticas y presidentes o directores de entes autónomos y gubernamentales. El nuevo procedimiento de nombramiento residencia en el presidente de la República la propuesta (aunque literalmente se diga elección), quedando en manos de la Asamblea la ratificación o veto de los propuestos. La ratificación deberá producirse en un plazo máximo quince días hábiles, con el voto favorable del 60\% del total de diputados. De no producirse la ratificación el presidente de la República deberá proceder a un nuevo nombramiento dentro del plazo de 30 días hábiles, debiendo 
someterse el nuevo nombramiento al procedimiento de ratificación ya establecido.

2. "Elegir" (Nueva redacción Art. 138.9, Constitución) a otra serie de altos funcionarios: a) al superintendente y vicesuperintendente general de bancos y otras instituciones financieras; b) al fiscal general de la República, quien estará a cargo del Ministerio Público y al fiscal general adjunto de la República, quienes deberán tener las mismas calidades que se requieren para ser magistrados de la Corte Suprema de Justicia; c) los miembros del Consejo Superior de la Contraloría General de la República; d) al procurador y subprocurador para la Defensa de los Derechos Humanos; e) al superintendente y a los intendentes de Servicios Públicos; f) al director y al subdirector del Instituto de la Propiedad Reformada Urbana y Rural.

El nuevo procedimiento de elección residencia en el presidente de la República y en la Asamblea, a la sazón, la propuesta, quedando en manos de la Asamblea la ratificación o veto de los propuestos. A diferencia de los ministros y altos cargos, la propuesta es mucho más diversa, extrayéndose de listas separadas - una elaborada por el presidente y otra por la Asamblea- para cada cargo y previas consultas con la "asociaciones civiles pertinentes", por mayoría cualificada del 60\% de la Asamblea Nacional.

3. "Rechazar" el veto del presidente a un proyecto de ley (nuevo Art. 143, Constitución), en los siguientes términos:

A partir de la entrada en vigor de la reforma, cuando un proyecto de ley vetado, ya sea total o parcialmente, por el presidente de la República, el veto no paralizará la iniciativa legislativa existiendo un procedimiento que disciplina la posibilidad de reactivación del mismo. En concreto, el presidente de la República deberá fundamentar los motivos del veto y devolverlo a la Asamblea Nacional. Ésta podrá rechazar el veto por mayoría absoluta de diputados, en cuyo caso el presidente de la Asamblea Nacional mandará a publicar la ley. Cuando el veto sea parcial, éste deberá contener expresión de motivos de cada uno de los artículos vetados. La Asamblea Nacional, con la mitad más uno de sus miembros podrá rechazar el veto de cada artículo, en cuyo caso el presidente de la Asamblea Nacional mandará a publicar la ley.

Es necesario recordar que estas reformas tenían la denominada "colita” (condición) sobre el consenso entre los poderes del Estado para poder ponerlas en vigor; la misma fue declarada inconstitucional por la Corte Suprema, en consecuencia, el 20 de enero de 2007 entró en vigor en virtud de la Ley Marco para la Estabilidad y Gobernabilidad del País, Ley No. 558, de 19 de octubre de 2005. 
Junto con la reforma constitucional, entraron en vigor:

1. La Ley de la Superintendencia de Servicios Públicos, que crea una superintendencia y cuatro intendencias: Telcor, INE, INAA y Atención de Usuarios.

2. La ley creadora del Instituto de la Propiedad Urbana y Rural, con facultades omnímodas para resolver en lo administrativo con carácter de exclusividad, todos los problemas de la propiedad urbana y rural, haciendo desaparecer la Comisión Nacional de Revisión, las facultades sobre la propiedad del Ministerio de Hacienda y las facultades sobre la Procuraduría General de Justicia en lo que se refiere a la notaría del Estado.

3. La Ley Orgánica de la Seguridad Social, que contempla la creación de un superintendente de la Seguridad Social nombrado por listas de la presidencia de la República y la Asamblea Nacional, y además establecer prestaciones médicas iguales a jubilados y trabajadores activos.

\subsection{LA REFORMA CONSTITUCIONAL FUTURIBLE}

Como es sabido, la Asamblea Nacional de Nicaragua creó una "Comisión especial para elaborar el anteproyecto de reformas constitucionales", integrada por siete diputados en reparto proporcional al pleno. ${ }^{10}$ El día 2 de octubre de 2007, el líder de la bancada sandinista dio a conocer que su partido prepara una iniciativa de reformas constitucionales.

Oficialmente, a la hora de cerrar este artículo, no existe todavía una propuesta de reforma del gobierno, tampoco un posicionamiento claro del resto de partidos pese a que también tienen sus propias comisiones internas que elaboran sus propias propuestas de enmiendas. No obstante, pueden identificarse los aspectos que se han ido filtrando como, cuando menos, objeto de discusión de cara a la reforma. ${ }^{11}$

Sin duda la cuestión de la reelección presidencial es en Nicaragua, como en un número significado de países latinoamericanos, un tema de la agenda de reforma, y se presenta en Nicaragua con algunos matices respecto al debate fuera, particularmente porque se promueve en el contexto de la profundización en el debilitamiento de la jefatura del Estado republicano a favor de un régimen parlamentario. De otro lado porque se

\footnotetext{
${ }^{10}$ Información obtenida el 3 de octubre de 2007 en: http//:www.asamblea.gov.ni

${ }^{11}$ Los puntos que se mencionan a continuación, fueron extraídos el 3 de octubre de 2007 de: http:// www.radiotrece.com.mx/2007/10/02/nicaragua-busca-reforma-constitucional/, quien a su vez lo tomó de la agencia noticiosa AFP, según cable del día 2 de octubre de 2007.
} 
plantea en un debilitamiento del Frente Sandinista, entre aquellos pocos líderes históricos que se han mantenido junto a Ortega y los nuevos que se han promovido desde el entorno de la mujer del presidente, que ejerce de facto como vicepresidenta política. Es decir, que aparece como un interés cupular y no una demanda social identificable, como ocurre en otros países por la identificación de las bases con un liderazgo específico, caso de Venezuela o Bolivia.

La reforma pasa por retocar el vigente artículo 147 de la Constitución nicaragüense, que reza: "No podrá ser candidato a Presidente ni Vicepresidente de la República: a) el que ejerciere o hubiere ejercido en propiedad la Presidencia de la República en cualquier tiempo del periodo en que se efectúa la elección para el periodo siguiente, ni el que la hubiera ejercido por dos periodos presidenciales; b) el Vicepresidente de la República o el llamado a reemplazarlo, si hubiere ejercido su cargo o el Presidente en propiedad durante los doce meses anteriores a la fecha en que se efectúa la elección para el periodo siguiente."

Ligada a esta cuestión, aparece la de la ampliación del mandato presidencial, que actualmente es de cinco años, a seis o a siete.

En segundo lugar, como hemos adelantado, la reforma pasa por continuar el viaje hacia un sistema parlamentario. Como ya vimos en momentos precedentes de este estudio, de acuerdo con la Constitución nicaragüense de 1987, la forma de poder es presidencial, republicana y representativa.

Una de las tesis que se ha postulado desde el sector afín al presidente, es la de dotar al Parlamento de facultades para elegir, por mayoría absoluta de votos (67 votos) al jefe de gobierno o primer ministro. Sería una nueva figura en el ordenamiento nicaragüense, lo que supondría una vuelta de tuerca clave hacia el modelo parlamentario. Dicha vuelta de tuerca, permitiría a Ortega cumplir su objetivo último de mantenerse en el poder sin necesidad de pasar por el delicado trance de reformar el mandato del presidente. Esta estrategia implicaría lógicamente la supresión de las elecciones presidenciales de 2011.

La predicha estrategia podría perfectamente entrar en un pacto dirigido, en un primer momento, a que Ortega se postule para el Congreso. En esta lógica, contaría con el apoyo del liberalismo tradicional del expresidente Arnoldo Alemán del Partido Liberal Constitucionalista, y pretendería retomar un bipartidismo (FSLN y PLC). Bipartidismo que como sabemos se rompió en las elecciones presidenciales con un candidato del nuevo liberalismo: Montealegre. Tanto el candidato como el partido son un invento 
de Estados Unidos que, como tal, tiene una implantación muy débil en el país, y en consecuencia, tendría una fuerza muy distinta en elecciones presidenciales que en las parlamentarias, y en unas parlamentarias dentro de un sistema parlamentario que en la que conformaron el parlamento actual: parlamentarias en sistema presidencial con coincidencia de campaña y fechas en la elección.

Después de las elecciones, la estrategia de Eduardo Montealegre ha sido deshojar la margarita hasta las nuevas elecciones, postularse como segunda fuerza y única alternativa al dar por difunto al PLc. Pero aparte de las debilidades de Montealegre, que es básicamente vendedor de humo y de la receta que llevó a Nicaragua donde está, la realidad juega en su contra. Su imagen y su discurso sirven para los fogonazos de la campaña corta e intensa, no para fajarse en la vida parlamentaria durante años. Por otra parte, y esto es más importante, el FsLn y el PLc hace algún tiempo que decidieron que era mejor partir la tarta que arriesgarse a no tener nada. Por todo ello, no es de extrañar que el opositor más acérrimo a este plan de reforma sea el excandidato presidencial en las elecciones de 2006 y paladín del sector más conservador de la fragmentada derecha local. ${ }^{12}$

Conviene finalmente recordar que la reforma constitucional debe ser aprobada en dos legislaturas, con elecciones dividiendo el Parlamento que la inicia del que la culmina, por un mínimo de 56 de los 92 votos del Congreso, ${ }^{13}$ los cuales pueden ser reunidos fácilmente conforme al pacto

\footnotetext{
${ }^{12}$ La Voz del Sandinismo, extraído el 3 de octubre de 2007 de: http://www.lavozdelsandinismo.com/ nicaragua/2007-10-02/parlamentarismo-nueva-palabra-de-orden-en-nicaragua/

${ }^{13}$ La Constitución prevé en sus artículos 191 al 195 la reforma de la misma: Art. 191.- La Asamblea Nacional está facultada para reformar parcialmente la presente Constitución Política y para conocer y resolver sobre la iniciativa de reforma total de la misma.

La iniciativa de reforma parcial corresponde al Presidente de la República o a un tercio de los diputados de la Asamblea Nacional.

La iniciativa de reforma total corresponde a la mitad más uno de los diputados de la Asamblea Nacional. Art. 192.- La iniciativa de reforma parcial deberá señalar el o los artículos que se pretenden reformar con expresión de motivos; deberá ser enviada a una comisión especial que dictaminará en un plazo no mayor de sesenta días. El proyecto de reforma recibirá a continuación el trámite previsto para la formación de la ley. La iniciativa de reforma parcial deberá ser discutida en dos legislaturas.

Arto. 193.- La iniciativa de reforma total seguirá los mismos trámites fijados en el artículo anterior, en lo que sea conducente a su presentación y dictamen.

Al aprobarse la iniciativa de reforma total, la Asamblea Nacional fijará un plazo para la convocatoria de elecciones de Asamblea Nacional Constituyente. La Asamblea Nacional conservará su mandato hasta la instalación de la nueva Asamblea Nacional Constituyente.

Mientras no se apruebe por la Asamblea Nacional Constituyente la nueva Constitución, seguirá en vigencia la presente Constitución.

Art. 194.- La aprobación de la reforma parcial requerirá del voto favorable del 60 por ciento de los diputados. En caso de aprobación de la iniciativa de reforma total se requerirá los dos tercios del total de los diputados. El Presidente de la República promulgará la reforma parcial y en este caso no podrá
} 
político que se mantiene en el plano legislativo, con los 40 diputados sandinistas y los 25 legisladores liberales.

\section{Conclusiones}

Las elecciones en Nicaragua pusieron de manifiesto, nuevamente, la voluntad de cambio de Latinoamérica. El Frente Sandinista, en principio y a pesar de las transas históricas que hemos comentado, representaba el cambio político. Sería quizá más preciso decir que se identificaba como cambio. Un indicador de dicho cambio fue, sin duda, la expresión de la mayoría durante las elecciones y tras el triunfo electoral. Otro indicador, más fiable, por ser menos volátil y maleable que la población, fue la expresión de las fuerzas reaccionarias frente al cambio. Éstas, nacionales e internacionales, políticas, económicas y mediáticas, azuzaron el miedo como si nada hubiese cambiado desde la salida del primer Frente.

Las manifestaciones de las fuerzas contra el cambio se llevaron ciertamente al plano electoral. Ahí se observó que los riesgos del fraude electoral siempre están presentes, pero progresivamente se van cerrando los frentes. Esta progresión podría resumirse en la siguiente regla: cuanto mayores sean la pluralidad de la observación electoral internacional y la implantación del partido que representa el cambio, menores son las posibilidades de fraude electoral y de deslegitimación mediática de los resultados. Además de estas dos variables, en Nicaragua se da la peculiaridad de que las transas y cuoteo del Frente con los liberales le hicieron tener posiciones hasta en el máximo órgano electoral.

Sin embargo, visto lo visto, la virulencia de las fuerzas contra el cambio no parecen justificarse, salvo si se estima que: Montealegre era todavía menos cambio y más servilismo que este Frente; que en política internacional el Frente podría ser, al menos en algunos casos, un voto "bolivariano"; y si se asume, como es obvio, que la inteligencia reaccionaria, formal y material, ya sabía que el Frente segundo no era lo que era, evitar su acceso a la presidencia, retrasaría otro mandato al Frente y retrasaría la creación de un Frente auténtico.

Esta realidad encuentra refrendo en la reforma constitucional, la última y la prevista.

ejercer el derecho al veto.

Art. 195.- La reforma de las leyes constitucionales se realizará de acuerdo al procedimiento establecido para la reforma parcial de la Constitución, con la excepción del requisito de las dos legislaturas. 
La reforma constitucional apoyada por el Frente Sandinista, con carácter previo a las elecciones que le dieron el segundo triunfo electoral en su historia, maniató parcialmente a Daniel Ortega, por eliminar el sistema presidencialista y tornarlo en uno semipresidencialista. La apuesta por dicha posición denunció varias cosas de importancia variable. De forma sustantiva supuso constitucionalizar la estrategia sandinista de alcanzar las mayores cuotas de poder de forma estructural. Dicha estrategia vino provocada por las sucesivas pérdidas en la elección presidencial y la negativa de la cúpula de Ortega de abrir paso a otras generaciones.

La predicha estrategia llevaba implícita el abandono de la materia del proyecto sandinista tradicional; la histórica renuncia se acució, afectando también al discurso, durante la campaña electoral. El colofón de ese abandono sería el apoyo a la reforma restrictiva de la histórica ley del aborto nicaragüense pocas fechas antes del lanzamiento de la campaña y siguió con el abandono de los símbolos durante la campaña. El gobierno conformado y los meses de gobiernos que se han vivido hasta octubre de 2007 certifican lo peor: Ortega, su señora, y la cúpula sandinista que se ha plegado al predicho proceso, quieren gestionar el poder y no como antaño transformar la realidad que ahoga al débil. En este contexto cuadra perfectamente la reforma constitucional que se está barajando: pérdida de poder institucional a favor de los liberales a cambio de mantenerse en el poder. Situados ahí, han decidido, no sin razón, que la forma menos costosa de hacerlo es transitar hacia el parlamentarismo, con independencia de que se ampliaría el mandato presidencial si se pudiese.

\section{REFERENCIAS}

Cabo Martín, Carlos de, La reforma constitucional en la perspectiva de las fuentes del derecho, Trotta, Madrid, 2003.

Cárdenas Gracia, Jaime F., Partidos politicos y democracia, Cuadernos de divulgación de la cultura democrática, número 8, Instituto Federal Electoral, México, 2001.

Enciclopedia nicaragüense, en http://enciclopedianicaraguense.com/Nicaragua.htm

Farrell, David M., Electoral systems: a comparative introduction, Basingstoke, Hampshire: Palgrave, 2001.

Información Asamblea, en tgh//:www.asamblea.gov.ni 
Katz, R. S, A Theory of Parties and Electoral systems, Johns Hopkins University, Baltimore, 1980.

La Voz del Sandinismo, extraído de: http://www.lavosdelsandinismo.com

Lijphart, A., Sistemas electorales y sistemas de partidos: un estudio de 27 democracias, Centro de Estudios Constitucionales, Madrid, 1995.

Nohlen, Dieter, Sistemas electorales y partidos políticos, Fondo de Cultura Económica, México, 1998.

Ortega Villodres, C., Los sistemas de voto preferencial. Un estudio de 16 democracias, Centro de Investigaciones Sociológicas, Madrid, 2004.

Sartori, Giovanni, Teoría de la democracia, t. II, Alianza, Madrid, 1988.

Vega, Pedro de, La reforma constitucional y la problemática del poder constituyente, Tecnos, Madrid, 1985. 